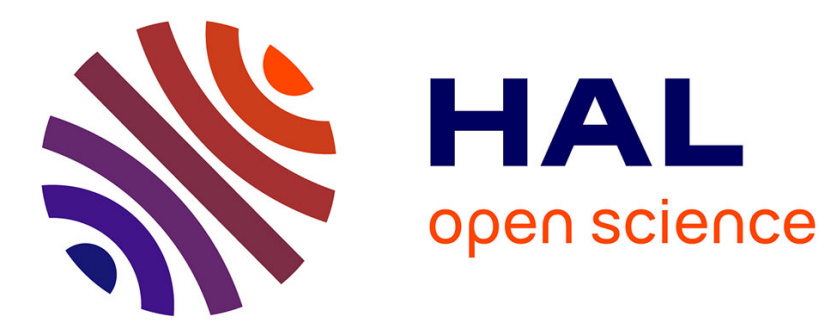

\title{
Purification of Ultra-High Purity Aluminum
}

\author{
E. Hashimoto, Y. Ueda, T. Kino
}

\section{- To cite this version:}

E. Hashimoto, Y. Ueda, T. Kino. Purification of Ultra-High Purity Aluminum. Journal de Physique IV Proceedings, 1995, 05 (C7), pp.C7-153-C7-157. 10.1051/jp4:1995715 . jpa-00254008

\section{HAL Id: jpa-00254008 https://hal.science/jpa-00254008}

Submitted on 1 Jan 1995

HAL is a multi-disciplinary open access archive for the deposit and dissemination of scientific research documents, whether they are published or not. The documents may come from teaching and research institutions in France or abroad, or from public or private research centers.
L'archive ouverte pluridisciplinaire HAL, est destinée au dépôt et à la diffusion de documents scientifiques de niveau recherche, publiés ou non, émanant des établissements d'enseignement et de recherche français ou étrangers, des laboratoires publics ou privés. 


\title{
Purification of Ultra-High Purity Aluminum
}

\author{
E. Hashimoto, Y. Ueda and T. Kino*
}

Laboratory of Crystal Physics, Faculty of Science, Hiroshima University, Higashi-Hiroshima 739, Japan

* Hiroshima-Denki Institute of Technology, Hiroshima 739-03, Japan

\begin{abstract}
Zone refining was applied experimentally to high-purity aluminium produced by a combination of the three-layer electrolytic refining process and the segregation process. The cropping procedure was effective in increasing the efficiency of zone refining. The highest residual resistance ratio $R(300 \mathrm{~K}) / R(4.2 \mathrm{~K})$ obtained was more than 150000 in the bulk value, corresponding to a refined purity better than $99.99999 \%$.
\end{abstract}

\section{INTRODUCTION}

Many properties of materials are very sensitive to the presence of impurities even in trace amounts. For this reason, in recent years, the necessity for high-purity materials has been fast increasing in fundamental research as well as in practical applications.

In our laboratory, considerable efforts have been made to obtain high-purity aluminium by zone refining in order to investigate the intrinsic properties of metals. The purity of aluminium so far obtained was $99.9999 \%$, and its residual resistance ratio in bulk was about 30000 [1]. However, recent development of very high precision techniques enable us to detect impurity effects even in ppm amounts or less. This urges on us the necessity of further purification.

The main purpose of this work is to obtain $99.99999 \%$ aluminium by zone refining. In purification utilizing the segregation phenomenon during solidification, refined purity varies depending on the raw purity of the material. Therefore, as starting material, we adopted high-purity aluminium (> $99.999 \%$ ) produced by a combination of the three-layer electrolytic refining process and the segregation process $[2,3]$. Furthermore, in order to increase the efficiency of zone refining, a cropping procedure [4] was applied to zone melting.

\section{EXPERIMENTAL PROCEDURE}

The starting material used in this work was $99.9999 \%$ pure aluminium supplied by the Sumitomo Chemical Co., Ltd., and its residual resistance ratio in bulk was about 15000 . The material rod $(10 \mathrm{~mm} \times 22 \mathrm{~mm} \times$ 
$22 \mathrm{~mm} \times 900 \mathrm{~mm}$ ) was first scraped to remove surface oxides and rinsed in acetone and in distilled water. Then the rod was set on a reactor grade graphite boat inside a quartz tube. This assembly was attached to a vacuum system with a cryosorption pump or a sputter ion pump.

Zone melting was performed by induction heating in a vacuum better than $2 \times 10^{-7} \mathrm{~Pa}$. Two procedures were applied to zone melting: one was the conventional procedure, in which refining was carried on throughout the rod; another the cropping procedure [4], in which impurity-enriched regions in both top and tail sides of the rod were separated after each zone pass. The zone speed and the zone length were fixed at $55 \mathrm{~mm} . \mathrm{h}^{-1}$ and $30 \mathrm{~mm}$, respectively, in the light of the optimum conditions determined previously [1].

Five aluminium rods, A, B, C, D and E, were zone refined in the following way :

Rods A and B: zone-passed once and 10 times, respectively, by use of the conventional method.

Rod C: zone-passed 5 times conventionally, and subsequently 5 times by a repetition of the cropping procedure. In the latter procedure, at least complete zone lengths were separated successively from both top and tail sides after each zone pass.

Rods D and E: zone-passed 30 and 60 times, respectively, only by use of the cropping method. In this case, the material quantity separated from each side was $1 / 8^{1 / 4}$ of zone length.

The efficiency of zone refining was estimated in terms of bulk residual resistance ratio $R R R_{\mathrm{b}}$ defined by $\rho(300 \mathrm{~K}) / \rho_{\mathrm{b}}(4.2 \mathrm{~K})$, where $\rho(300 \mathrm{~K})$ is the electrical resistivity measured at $300 \mathrm{~K}$ and $\rho_{\mathrm{b}}(4.2 \mathrm{~K})$ is the size-corrected resistivity at $4.2 \mathrm{~K}$.

The samples for the resistance measurement were prepared in the following way. For zone-refined aluminium rods $\mathrm{A}$ and $\mathrm{B}$, small pieces were first cut from the rod, rolled to $0.5 \mathrm{~mm}$ thickness, and then cut in the form of $0.5 \mathrm{~mm} \times 3 \mathrm{~mm} \times 60 \mathrm{~mm}$ as the sample. For rods $\mathrm{C}, \mathrm{D}$ and $\mathrm{E}$, the single-crystal samples of $1 \mathrm{~mm} \times 3 \mathrm{~mm} \times 20 \mathrm{~mm}$ were cut parallel with the rod axis by spark erosion. All the samples were chemically etched in aqua regia and rinsed in distilled water. Then zone-refined aluminium wires $0.3 \mathrm{~mm}$ in diameter were spot-welded on to the sample as the electrodes for the resistance measurement. The samples thus prepared were annealed in air at $573 \mathrm{~K}$ for $3 \mathrm{~h}$, and furnace-cooled to room temperature.

The resistance measurement was performed by the standard four-terminal method. The resistance at $4.2 \mathrm{~K}$ was measured with a dc comparator potentiometer with a sensitivity of $\pm 0.5 \mathrm{nV}$ (Guildline Model 9930 ), or with a superconducting chopper amplifier with a sensitivity of $2 \mathrm{pV}$. The measurement at $300 \mathrm{~K}$, on the other hand, was made with the former instrument for all the samples.

\section{RESULTS AND DISCUSSION}

The starting material used was analyzed by glow discharge mass spectrometry (GDMS) [2]. According to a typical analysis, the main impurities are:

$\mathrm{B}$ (0.02); F (<0.14); Na (0.05); Mg (0.27); Si (0.57); P (0.07); Cl (0.03); K (<0.07);

$\mathrm{Sc}$ (0.06); Ti (0.03); V (0.02); Cr (0.01); Fe (0.04); Cu (0.15); Se (0.02); Cd (0.02).

The figure in parentheses indicates the impurity concentration in at.ppm unit. Other impurities are all of less than 10 at.ppb. The analysis, in connection with the electrical resistivity of unit impurity concentration, satisfactorily explains the residual resistance ratio of about 15000 in bulk.

The existence of $\mathrm{Sc}, \mathrm{Ti}, \mathrm{V}$ and $\mathrm{Cr}$ in the starting material will restrict the gain in purity in the conventional zone refining procedure, since the distribution coefficient $k \approx 0.9$ for $\mathrm{Sc}$ while $k>1$ for Ti, $\mathrm{V}$ and $\mathrm{Cr}$. Besides, these impurities make a large contribution to the electrical resistivity. 
Figure 1 shows the bulk residual resistance ratio $R R R_{\mathrm{b}}\left[=\rho(300 \mathrm{~K}) / \rho_{\mathrm{b}}(4.2 \mathrm{~K})\right]$ plotted as a function of distance from the top in the last zone pass for zone-refined aluminium rods $\mathrm{A}, \mathrm{B}, \mathrm{C}, \mathrm{D}$ and E. Here, $\rho(300 \mathrm{~K})=27.33 \mathrm{n} \Omega \cdot \mathrm{m}[5]$. The size correction of the resistivity $\rho(4.2 \mathrm{~K})$ at $4.2 \mathrm{~K}$ was carried out numerically according to the Fuchs-Sondheimer theory [6], assuming that the specularity parameter $p=0$ and that the product of bulk resistivity and bulk mean free path $\rho_{\mathrm{b}} l_{\mathrm{b}}=0.82 \mathrm{f} \Omega \cdot \mathrm{m}^{2}[7,8]$. The former assumption is reasonable, since the sample surface is rather rough after the etching [7].

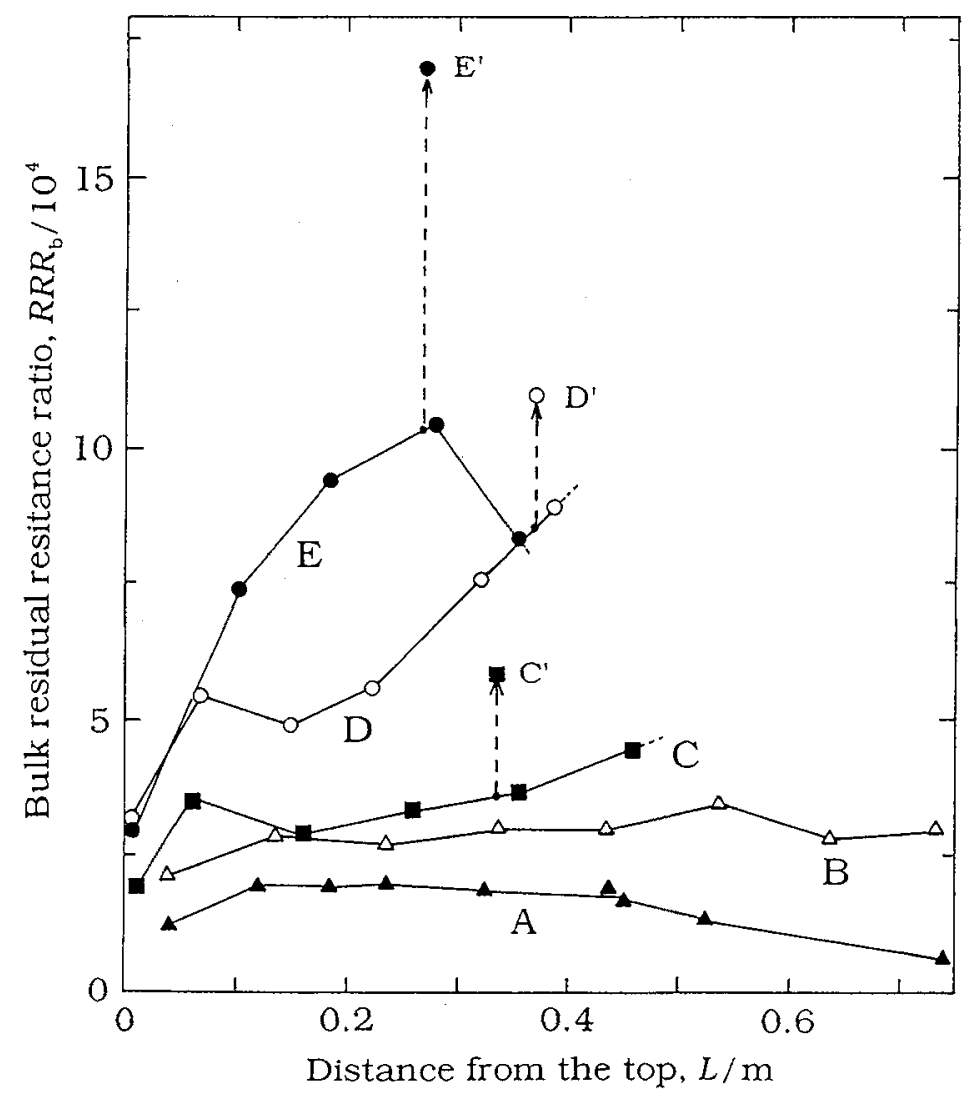

Figure 1: Bulk residual resistance ratio $R R R_{\mathrm{b}}$ plotted as a function of distance from the top in the last zone pass for zone-refined aluminum rods A, B, C, D and E. Rods $\mathrm{A}$ and $\mathrm{B}$ : zone-passed once and 10 times, respectively, by use of the conventional procedure. Rod C: zone-passed 5 times conventionally and subsequently 5 times by use of the cropping procedure. Rods D and E: zone-passed 30 and 60 times, respectively, by a repetition of the cropping procedure. The symbols denoted by $\mathrm{C}^{\prime}$, $\mathrm{D}^{\prime}$ and $\mathrm{E}^{\prime}$ indicate the values of $R R R_{\mathrm{b}}$ along the $<110>$ current direction in single crystals with the $\{110\}$ surface, prepared from zone-refined aluminum rods $C, D$ and $E$, respectively. 
The $R R R_{\mathrm{b}}$ in rod $\mathrm{A}$, zone-passed once conventionally, is about 20000 in the first half, while it decreases with the distance from the top in the second half. The main impurities remaining in the purer half of the rod are:

$\mathrm{Na}(<0.12) ; \mathrm{Mg}$ (0.03); $\mathrm{Si}(0.42)$; $\mathrm{Sc}(0.07)$; $\mathrm{Ti}(0.023) ; \mathrm{V}$ (0.018); $\mathrm{Cr}(0.015) ; \mathrm{Fe}(0.03) ; \mathrm{Cu}(0.08)$.

These results yield a $R R R_{\mathrm{b}}$ of about 20000 which is consistent with the measured value. The $R R R_{\mathrm{b}}$ after 10 zone passes (rod $B$ ) reaches about 30000 in a large part of the rod. However, the analysis indicates that the major contribution (about $80 \%$ ) to $\rho_{\mathrm{b}}(4.2 \mathrm{~K}$ ) is due to $\mathrm{Sc}, \mathrm{Ti}, \mathrm{V}$ and $\mathrm{Cr}$, and that these impurities exhibit only a slight change in their distribution even after 10 zone passes; for example, Sc (0.07), Ti (0.023), $\mathrm{V}(0.014)$ and $\mathrm{Cr}(0.012)$ at a distance about $0.5 \mathrm{~m}$ from the top.

With the conventional procedure, the gain in purity per zone pass decreases with increasing numbers of zone passes. It becomes zero when approaching the ultimate impurity distribution. The establishment of the ultimate distribution is caused by impurity-enriched regions at both top $(k>1)$ and tail $(k<1)$ ends of the rod [9]. In addition, it has been pointed out that the slope and curvature of the impurity-concentration profile in these regions cause pronounced backward diffusion. A high diffusion rate competes with the segregation effect, leading to a plateau in the concentration profile. The resulting distribution is far from reaching the ultimate distribution without considering backward diffusion [4]. Therefore, it is very difficult to obtain $99.99999 \%$ aluminium only by a repetition of the conventional procedure.

With the cropping procedure, on the other hand, it has been shown that the gain in purity per zone pass becomes constant after a certain number of zone passes, and that the influence of backward diffusion is decreased [4]. Therefore, we applied the cropping procedure to zone melting in order to attain our purpose. In particular, this procedure may be effective in reducing the influence of backward diffusion of $\mathrm{Sc}$ atoms, since they can diffuse fast in aluminium with an activation energy of about $0.094 \mathrm{aJ}(0.6 \mathrm{eV})$ [10,11].

The $R R R_{\mathrm{b}}$ in rod $\mathrm{C}$, zone-passed 10 times by a combination of the conventional procedure and the cropping procedure, increases from about 20000 to 45000 with the distance from the top. This may be due to redistribution of impurities with $k>1$, such as $\mathrm{Ti}, \mathrm{V}$ and $\mathrm{Cr}$, and suggests the effectiveness of the cropping procedure. In fact, after repeating the cropping procedure 30 and 60 times, $R R R_{\mathrm{b}}$ increases rapidly and reaches about $90000(\operatorname{Rod} D)$ and $100000(\operatorname{rod} E)$, respectively. These values correspond to $99.99999 \%$ purity when the contribution to $\rho_{\mathrm{b}}(4.2 \mathrm{~K})$ is mainly due to $\mathrm{Sc}, \mathrm{Ti}, \mathrm{V}$ and $\mathrm{Cr}$ as expected from the analysis of rod B.

The results as shown in Fig. 1 clearly show that the cropping procedure is effective in increasing the efficiency of zone refining. However, $R R R_{\mathrm{b}}$ in rods $\mathrm{C}$ and $\mathrm{D}$ clearly exhibits a hump in the region at the top side. This may be due to competition between the effect of backward diffusion and the segregation effect of impurities with $k>1$, but details are not clear.

Recently we have found anisotropy of the bulk residual resistivity $\rho_{\mathrm{b}}(4.2 \mathrm{~K})$ in high-purity aluminium single crystals with the $\{110\}$ surface $[12,13]$. In theory as well as in experiment, the anisotropy of the bulk residual resistivity has not yet been predicted for a cubic system such as aluminium [14]. The results show that $\rho_{\mathrm{b}}(4.2 \mathrm{~K})$ increases in the order of the axis direction (i.e. current direction) $\left.<110\right\rangle,<111>$ and $<100>$. This anisotropy is important in the determination of the correct value of $R R R_{\mathrm{b}}$ in high-purity aluminium.

We therefore tried to measure $\rho_{b}(4.2 \mathrm{~K})$ along the axis direction (i.e. current direction) $<110>$ in single crystals with the $\{110\}$ main surface. The single crystals were cut from the zone-refined aluminium 
rods by spark erosion. The residual resistance ratio $R R R_{\mathrm{b}}$ thus obtained is also shown in Fig.1. The $R R R_{\mathrm{b}}$ of the single crystals is exceedingly large and becomes more than 150000 after repeating the cropping procedure 60 times, indicating that the resistivity due to impurities is less than the phonon resistivity at 4.2 $K$. This again emphasizes that the cropping procedure is effective in increasing the efficiency of zone refining, and that the anisotropy of the bulk residual resistivity $\rho_{\mathrm{b}}(4.2 \mathrm{~K})$ becomes significant with increasing refined purity.

In this work, we tried zone refining of high-purity aluminium produced by a combination of the threelayer electrolytic refining process and the segregation process. A cropping procedure was applied to zone melting to increase the efficiency of zone refining. The highest value for $R R R_{\mathrm{b}}$ obtained was more than 150000 , corresponding to $99.99999 \%$ aluminium.

\section{Acknowledgements}

The authors express their sincere thanks to the Sumitomo Chemical Co., Ltd. for the supply of aluminium samples and for the analysis of zone-refined aluminium by GDMS.

\section{References}

[1] Kino T., Kamigaki N., Yamasaki H., Kawai J., Deguchi Y. and Nakamichi I., Trans. JIM 17 (1976) 645.

[2] Magusa H., Sato T., Takahashi A. and Mda H., Sumitomo Chemical (1988-II) p. 69.

[3] Kondo M., Mda H. and Mizuguchi M., Journal of Metals 42 (1990) 36.

[4] Fischer D., J. Appl. Phys. 44 (1973) 1977.

[5] Kawata S. and Kino T., J. Phys. Soc. Jpn. 39 (1975) 684.

[6] Sondheimer E. H., Adv. Phys. 1 (1952) 1.

[7] Sambles J. R., Elsom K. C. and Sharp-Dent G., J. Phys. F: Met. Phys. 11 (1981) 1075.

[8] Ueda Y., Hosoda H. and Kino T., J. Phys. Soc. Jpn. 54 (1985) 3858.

[9] Pfann W. G., Zone melting (Wiley, New York, 1966).

[10] Hashimoto E., Miura K., Kino T., Matsushita R. and Koyama M., Japan. J. Appl. Phys. 18 (1979) 881 .

[11] Torma T., Kov'acs-Cset'enyi E. and Turmezey T., Defect and Diffusion Forum 66-69 (1989) 1479.

[12] Hashimoto E., Ueda Y., Tamura H. and Kino T., J. Phys. Soc. Jpn. 62 (1993) 4178.

[13] Ueda Y., Hashimoto E., Tamura H. and Kino T., This conference.

[14] Rossiter P. L., The electrical resistivity of metals and alloys (Cambridge University Press, Cambridge, 1986). 